\title{
SRF Controller in D-Statcom in Distribution Generation of PQ Improvement
}

\author{
K.Sailaja ${ }^{1}$, K. Swetha ${ }^{2}$
}

\begin{abstract}
This paper presents a modified instantaneous power control scheme of D-STATCOM for power factor and harmonic compensation. The proposed control strategy has been introduced in order to enhance some steady-state performances besides its functional elimination of power quality disturbances. Usage of SRF Controller to control the current.Power factor and harmonic current of a controlled feeder section are two vital roles in steady-state power distribution system operation. Utilizing an already installed D-STATCOM to achieve these additional control objectives can help system operators maximize overall system performances To verify its use, a 22-kV power distribution feeder with a three-phase rectifier load was tested.
\end{abstract}

\section{Introduction}

Electric power distribution network have become more increasingly important and plays an essential role in power system planning. This type of power systems has a major function to serve distributed customer loads along a feeder line, therefore under competitive environment of electricity market service of electric energy transfer must not be interrupted and at the same time there must provide reliable, stable and high quality of electric power . To complete this challenge, it requires careful design for power network planning. However, one might consider an additional device to be installed somewhere in the network. Such devices are one of capacitor bank, shunt reactor, series reactors, automatic voltage regulators and/or recently developed dynamic voltage restorers, distribution static compensator (D-STATCOM), or combination of them. The D-STATCOM can regulate magnitude of voltage at a particular AC bus, at the point where it is connected, via generating or absorbing reactive power from the system. From D-STATCOM literature, a majority of research works have been conducted in order to enhance electric power quality due to distribution voltage variations, e.g. voltage sags or swells. Apart from these voltage variations, the D-STATCOM is capable to enhance steady-state performances such as power factor and harmonic of a particular feeder portion. In this paper, a control scheme with constant power and sinusoidal current compensation is

exploited. In order to correct the power factor additionally, a power factor control loop is required and therefore included in the control block. SRF Controller is used in order to analyze system parameters easy with combination of hysterisis current controller this makes current controlling easy.

\section{Description Of D-Statcom Operation}

A D-STATCOM is a shunt device that regulates the system voltage by absorbing or generating reactive power at a point of coupling connection. The schematic diagram of a D-STATCOM is shown in Fig 1. The DSTATCOM is a solid state DC/AC power switching converter that consists mainly of a three-phase PWM voltage source converter (VSC) bridge having six IGBTs with associated anti-parallel diodes. It is connected to the distribution network via the impedance of the coupling transformer. A DC-link capacitor provides constant DC link voltage.

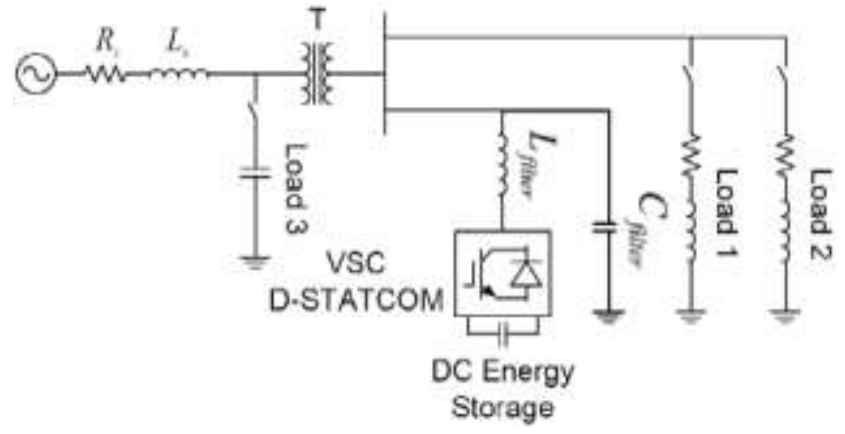

Fig. 1. Simplified power system equipped with a D-STATCOM

The output voltage of the D-STATCOM is generated by a DC/AC voltage source converter operated from an energy storage capacitor. From the DC input voltage, provided by a charged capacitor, the converter produces a 
set of controllable three-phase output voltages at the frequency of the AC power system. Each output voltage is in phase with and coupled to the corresponding $\mathrm{AC}$ voltage via coupling reactance. By varying the magnitude of output voltage produced, the reactive power exchange between D-STATCOM and AC system is controlled. If the amplitude of output voltage is increased (or decreased) above the AC system voltage, the converter generates (or absorbs) reactive power for the AC system. D-STATCOM acts as a shunt compensator connected in parallel to the system so that it can inject appropriate compensation.

currents [9-10]. The D- STATCOM has several advantages, compared to a conventional static var compensator (SVC). It gives faster responses and can produce reactive power at low voltage. Also, it does not require thyristor-controlled reactors (TCR) or thyristor-switched capacitors (TSC) that normally produce low order harmonics.

\section{Brief Of The Instantaneous Power Theory}

As the name implied, the instantaneous power theory [1] is based on a definition of instantaneous real and reactive powers in time domain. It is very useful not only in the steady-state but also in the transient state analysis for both three-phase systems with or without a neutral conductor. To illustrate the theory, let consider a set of instantaneous three phase quantity

$$
\text { for example } v_{a}, v_{b} \text { and } v_{c} \text {. It starts }
$$

with transforming a set of three-phase variables in the $a b c$

into $\alpha \beta 0$ coordinates. This transformation is so-called as the Clark transformation as described follows.

$$
\begin{aligned}
& {\left[\begin{array}{l}
v_{0} \\
v_{\alpha} \\
v_{\beta}
\end{array}\right]=\sqrt{\frac{2}{3}}\left[\begin{array}{ccc}
\frac{1}{\sqrt{2}} & \frac{1}{\sqrt{2}} & \frac{1}{\sqrt{2}} \\
1 & \frac{-1}{\sqrt{2}} & \frac{-1}{\sqrt{2}} \\
0 & \frac{\sqrt{3}}{2} & \frac{-\sqrt{3}}{2}
\end{array}\right]\left[\begin{array}{l}
v_{\alpha} \\
v_{b} \\
v_{c}
\end{array}\right]} \\
& {\left[\begin{array}{l}
i_{\odot} \\
i_{\alpha} \\
i_{\beta}
\end{array}\right]=\sqrt{\frac{2}{3}}\left[\begin{array}{ccc}
\frac{1}{\sqrt{2}} & \frac{1}{\sqrt{2}} & \frac{1}{\sqrt{2}} \\
1 & \frac{-1}{\sqrt{2}} & \frac{-1}{\sqrt{2}} \\
0 & \frac{\sqrt{3}}{2} & \frac{-\sqrt{3}}{2}
\end{array}\right]\left[\begin{array}{l}
i_{a} \\
i_{b} \\
i_{\sigma}
\end{array}\right]}
\end{aligned}
$$

In three-phase, three-wire systems, there is no zero sequence components. If $v_{0}$ and ${ }^{i_{0}}$ are both neglected. Instantaneous voltage, $\mathrm{v}$ and current phasors I, can be defined from their corresponding instantaneous $\alpha$ and $\beta$ components as follows.

$$
\begin{aligned}
& \mathrm{v}=v_{\alpha}+\mathrm{j} v_{\beta} \\
& \mathrm{I}=i_{\alpha}+\mathrm{j} i_{\beta}
\end{aligned}
$$

From (3) and (4), instantaneous complex powers, $\mathbf{s}$, can be defined as the product of the instantaneous voltage phasor and the complex conjugate of the instantaneous current phasor given in (5).

$$
\mathrm{S}=\mathrm{v} i^{*}=\left(v_{\alpha}+\mathrm{j} v_{\beta}\right)\left(i_{\alpha}+\mathrm{j} i_{\beta}^{i}\right)=\mathrm{p}+\mathrm{jq}
$$

Where

$\mathrm{P}=v_{\alpha} i_{\alpha}+v_{\beta} i_{\beta} \quad$ is the Instantaneous active power

$\mathrm{q}=v_{\beta} i_{\alpha}-v_{\alpha} i_{\beta}$ is the Instantaneous reactive power

The instantaneous complex power is useful. It can be applied for transient or steady-state analysis. The following equation is a compact form for the instantaneous real and reactive power definition and its inversion.

$$
\begin{aligned}
& {\left[\begin{array}{l}
p \\
q
\end{array}\right]=\left[\begin{array}{cc}
v_{\alpha} & v_{\beta} \\
-v_{\beta} & v_{\alpha}
\end{array}\right]\left[\begin{array}{l}
i_{\alpha} \\
i_{\beta}
\end{array}\right]} \\
& {\left[\begin{array}{l}
i_{\alpha} \\
i_{\beta}
\end{array}\right]=\frac{1}{\sqrt{v_{\alpha}^{2}+v^{2} \beta}}\left[\begin{array}{cc}
v_{\alpha} & -v_{\beta} \\
v_{\beta} & v_{\alpha}
\end{array}\right]\left[\begin{array}{l}
p \\
q
\end{array}\right]} \\
& \mathrm{P}=\bar{p}+\tilde{p} \\
& \mathrm{q}=\bar{q}+\tilde{q}
\end{aligned}
$$




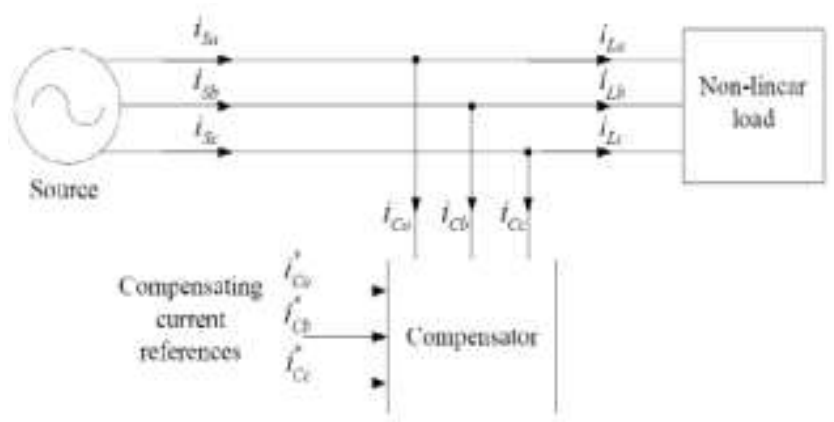

Fig. 2. Concept of shunt current compensation

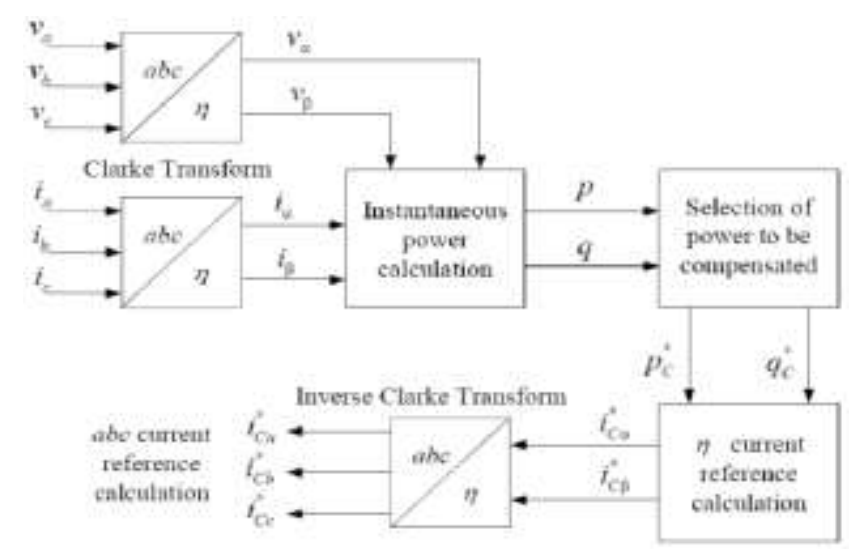

Fig. 3. Control block of shunt current compensation based on the instantaneous power theory

These two powers can be separated into average components $(\bar{p} \& \bar{q})$ and oscillating components $(\widetilde{p} \& \widetilde{q})$ as shown in (8) and (9). The average values of the both $\mathrm{p}$ and $\mathrm{q}$ agree with conventional real and reactive powers in AC circuits. The oscillating terms that naturally produce a zero mean give additional oscillating power flow without contribution of the energy transfer neither from the source to the load nor from the load to the source. one important application of the instantaneous power theory is the shunt current compensation as shown in fig.2. to achieve the compensation, the oscillating components of $\mathrm{p}$ and $\mathrm{q}$ must be

eliminated. The powers to be compensated can be simply determined by eliminating the oscillating real and reactive power components. Assume that the instantaneous powers of load and line current are calculated. The instantaneous current references to minimize the oscillating terms can be established with some efficient concepts. Fig. 3 shows a general idea of shunt current compensation based on the instantaneous power theory described in this section.

\section{Proposed Control Strategy for D-Statcom}

In general, power compensation by D-STACOM can have various functions such as elimination of power oscillation, improvement of power factor, elimination of harmonic current, etc. Under a balanced threephase supply condition, some criteria must be met to optimize the overall system compensation. The research conducted by [3-6] aimed to compensate the source current become purely sinusoidal and deliver the minimum average real power to the load. Although under non-linear loading it can guarantee only one optimal criterion, in this paper multiple objectives for shunt power compensation are proposed. In addition, power factor correction of a protected load can be included in the control scheme by zeroing reactive power supplied by the source.

As mentioned previously, the compensator must supply the oscillating power components to the load. In order to compensate the oscillating power flow by means of PWM converters, the DC voltage across the DC link capacitor must be large enough and kept constant at that value to stabilize the compensation. Therefore, DC link voltage regulator must be added to the control loop. To separate the oscillating real power components a low-pass filter is used. Together with the switching and ohmic losses of the PWM converter, the instantaneous real power reference is formed. Similarly, the instantaneous reactive power reference can be set as zero to achieve unity power factor. In practice, the reference signals for generating the switching pattern to drive IGBT gates are current waveforms, (7) is modified to equate the compensating current in $\alpha \beta$ coordinates as expressed in (10). Therefore, the $\alpha \beta$ current is transformed back to the $a b c$ coordinate for switching pattern generation as 
described by (11). With this power factor correction, the reactive power regulator is also added to the loop as shown in Fig. 4. The overview of the proposed control scheme can be depicted as shown in Fig. 5.

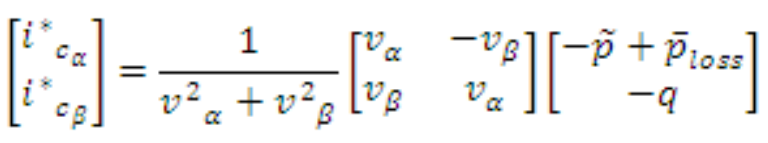

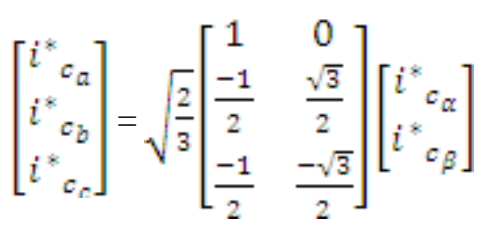

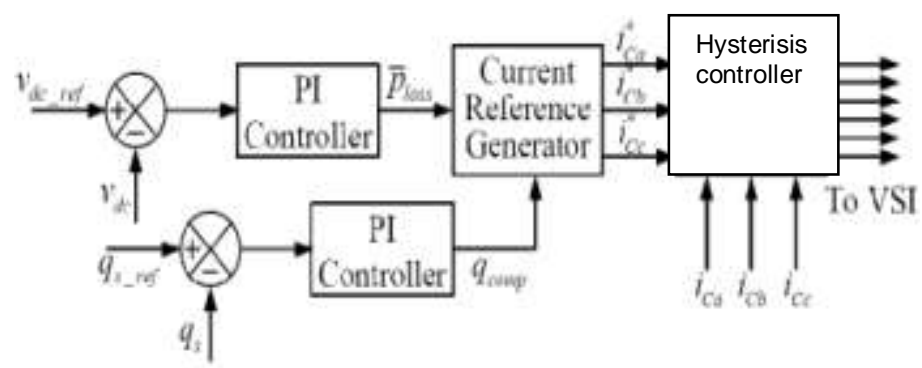

Fig. 4. Proposed control scheme with reactive power regulation

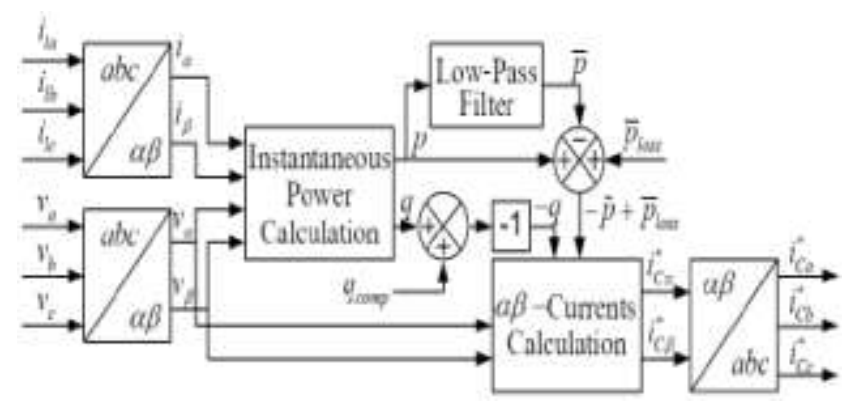

Fig. 5. Overall proposed control scheme

\section{V.}

SIMULATION RESULTS

To verify the use of the proposed control scheme in order to correct power factor and compensate harmonic current, a 22-kV power distribution feeder with three-phase rectifier loading as shown in Fig. 6 was employed. Table I gives information of the test system and D-STATCOM

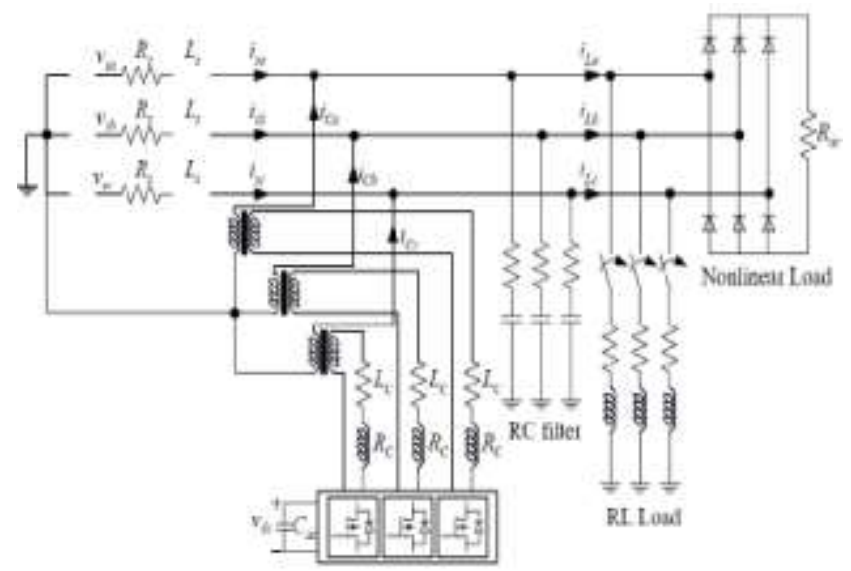

Fig. 6. 22-kV power distribution feeder with three-phase rectifier loading 
TABLE 1

PARMAETERS OF THE TEST SYSTEM

\begin{tabular}{|l|l|}
\hline System Parameters & Values \\
\hline Supply voltage & $22 \mathrm{kV}, 50 \mathrm{~Hz}$ \\
\hline RL balaneed load & $R=50 \Omega, L=100 \mathrm{mH}$ \\
\hline Nonlinear load & $\begin{array}{l}\text { 3-phase full wave rectifier } \\
\text { drawing a de cument of } 50 \mathrm{~A}\end{array}$ \\
\hline DC capacitor for D-STATCOM & $300 \mu \mathrm{F}$ \\
\hline Interface inductor & $L_{C}=2 \mathrm{mH}, R_{C}=0.1 \Omega$ \\
\hline Reference dc link vollaye & $v_{\text {dic } \text { _tf }}=9.5 \mathrm{kV}$ \\
\hline
\end{tabular}

The test was divided into two cases. The first case was used the control scheme introduced by [1]. Whereas, the second case was the proposed control scheme given in this paper. Both test cases were assigned to be operated with the same instruction. The test system was started from zero initial conditions with only the rectifier load. At $t=0.2 \mathrm{~s}$, the D-STATCOM was connected to the system via the point of coupling connection. At $t=0.5 \mathrm{~s}$, the $R L$ load was switched on to increase the system loading.

\section{A. Case 1:}

With the control strategy proposed by [1], the system response without D-STACOM in the time interval $0-0.2 \mathrm{~s}$ was shown in Fig. 7. At $t=0.2-0.5 \mathrm{~s}$, the D-STATCOM was connected to compensate the non-linear load as responses shown in Fig. 8. It can be seen that the source current was shaped to be nearly sinusoidal. However, due to the PWM operation of the D-STATCOM, higher-order harmonic components were inevitably experienced. At $t \geq 0.5 \mathrm{~s}$ when the $R L$ load switched, the source current was lagged the voltage at the point of coupling connection by 21.6 degree corresponding to 0.9298 power factor lagging. This can be seen in Fig. 8.

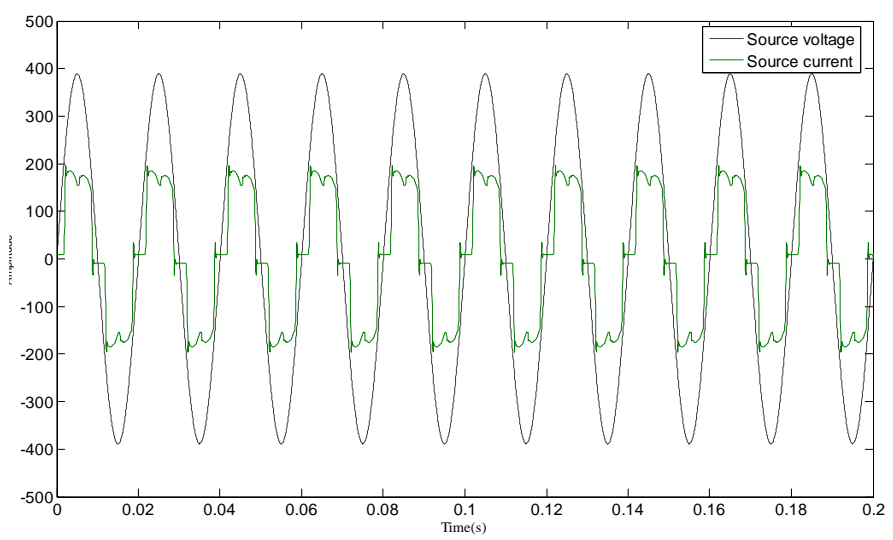

Fig. 7. Response during $t=0-0.2 \mathrm{~s}$ for case 1

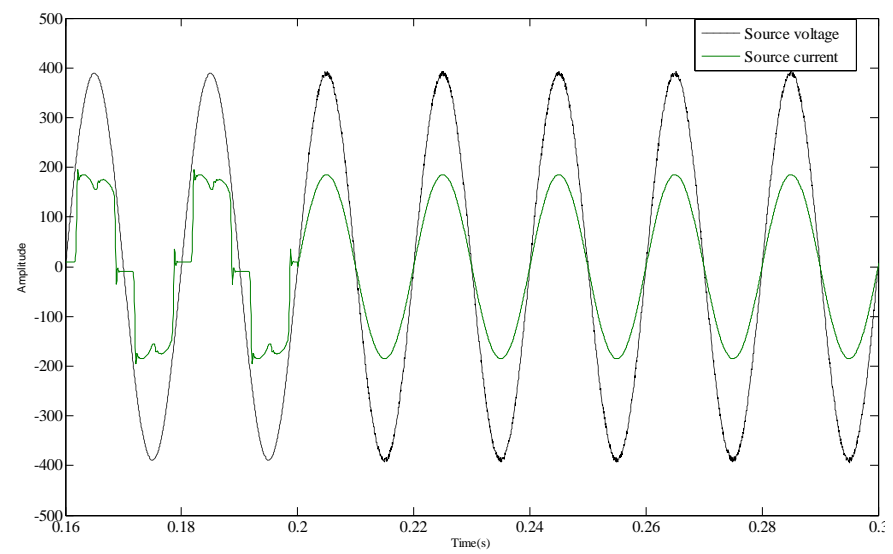

Fig. 8. Response during $t=0.2-0.5 \mathrm{~s}$ for case 1 


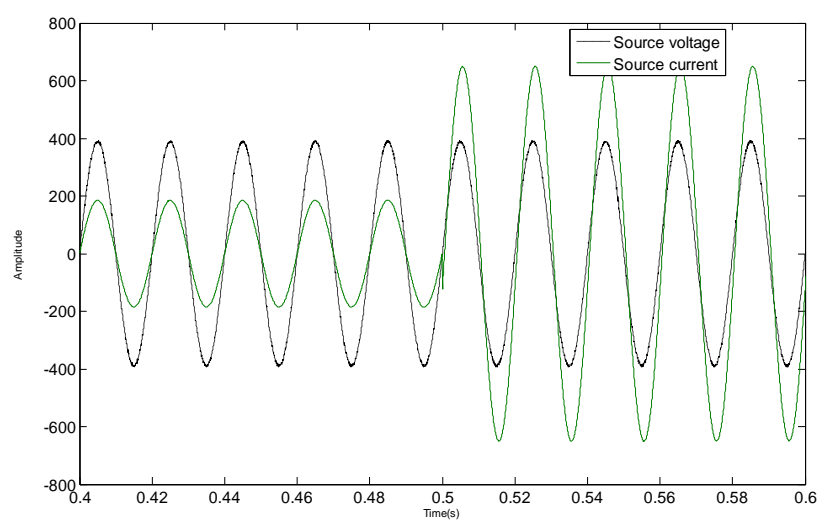

Fig. 9. Response during $t \geq 0.5 \mathrm{~s}$ for case 1

\section{B. Case 2:}

With the control strategy proposed in this paper, the system response without D-STACOM in the time interval $0-0.2 \mathrm{~s}$ was shown in Fig. 10. At $t=0.2-0.5 \mathrm{~s}$, the D-STATCOM was connected to compensate the non-linear load as responses shown in Fig. 11. It can be seen that the source current was shaped to be nearly sinusoidal. However, due to the PWM operation of the D-STATCOM, higher-order harmonic components were inevitably experienced. At $\mathrm{t} \geq 0.5 \mathrm{~s}$ when

the $R L$ load switched, the source current that was previously lagged the voltage at the point of coupling connection in case 1 was resumed to in-phase with the voltage waveform. This described the success of power factor correction by the reactive power control scheme made in this paper. This can be seen in Fig. 12.

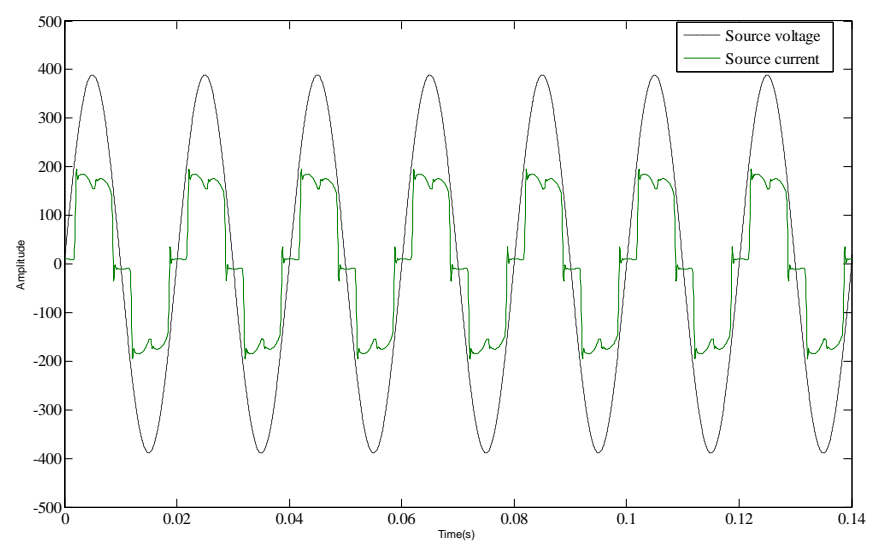

Fig. 10. Response during $t=0-0.2 \mathrm{~s}$ for case 2

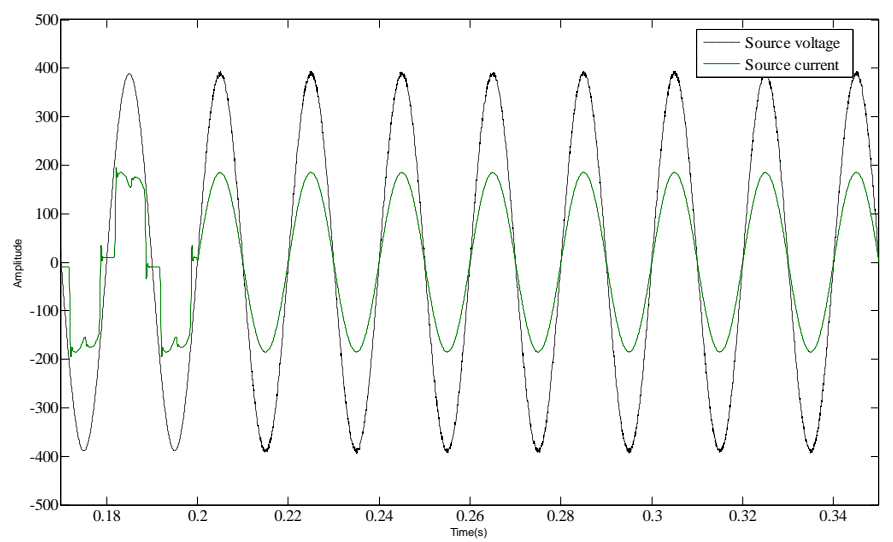

Fig. 11. Response during $t=0.2-0.5 \mathrm{~s}$ for

case 2 


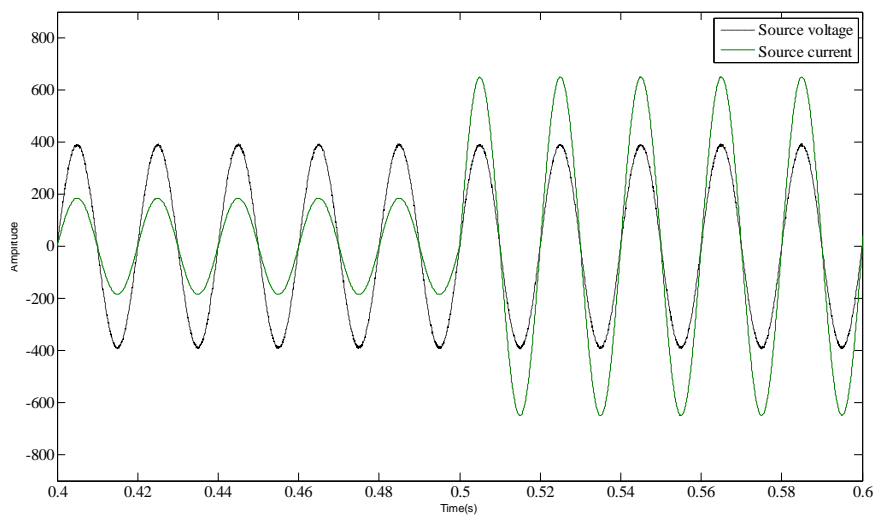

Fig. 12. Response during $t \geq 0.5 \mathrm{~s}$ for case 2

\section{Comparison:}

This section gives comparison between the results from both cases. Real powers, reactive powers and DC link voltages of each case were observed and then compared. Figs $13-15$ present the comparison of which for real power, reactive power and DC link voltage, respectively. The response of the observed reactive powers clearly confirmed that during the overall operation, the proposed control scheme can well perform the function of power factor correction. This can be seen with the zero reactive power for case 2 in Fig. 14.

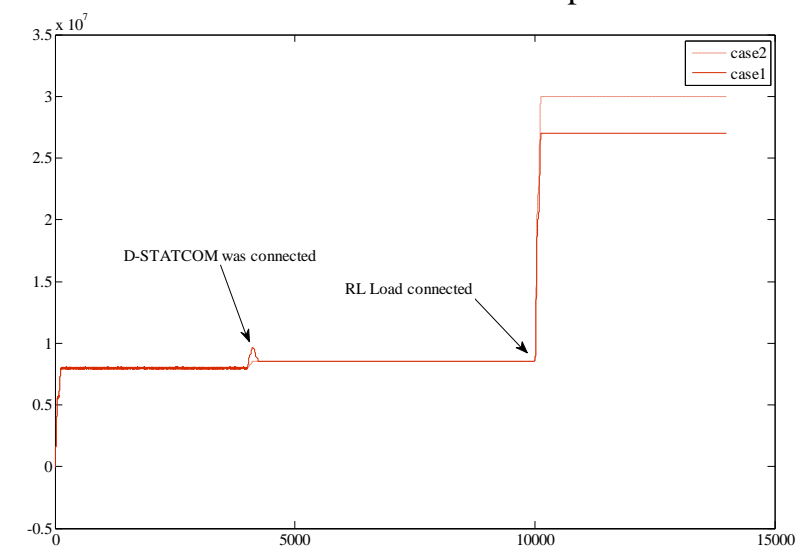

Fig. 13. Comparison of instantaneous real power regulation

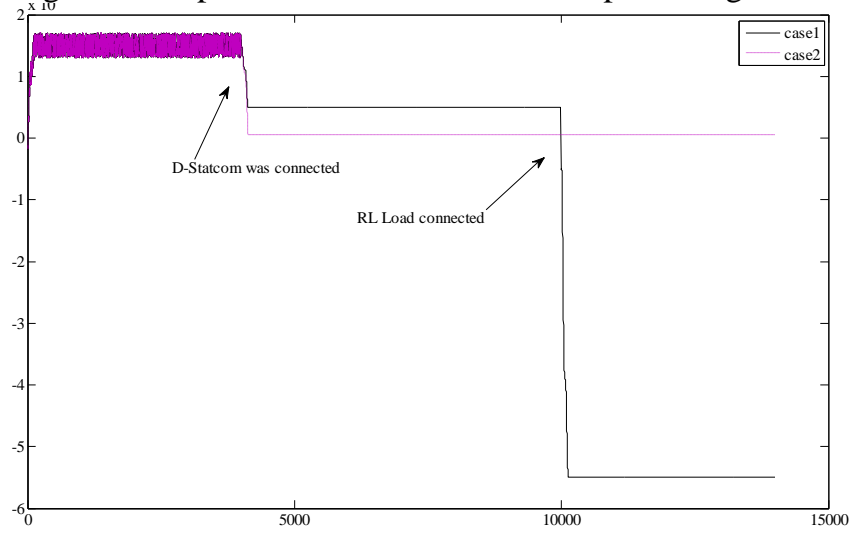

Fig. 14. Comparison of instantaneous reactive power regulation 


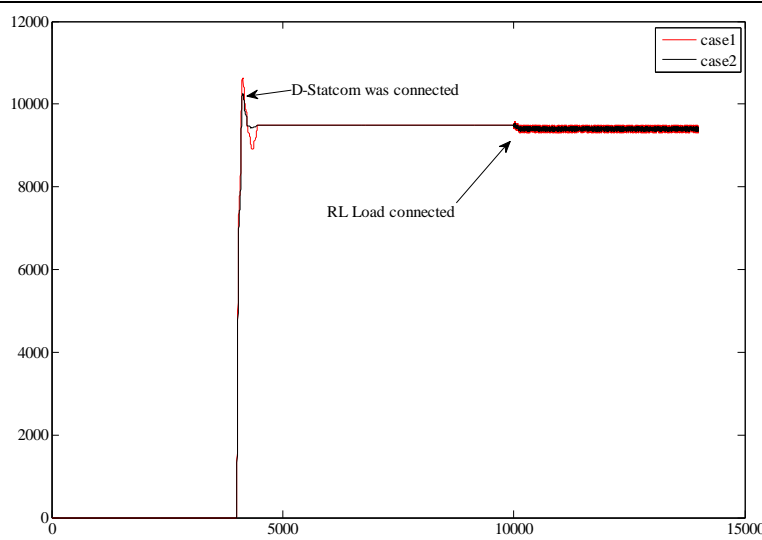

Fig. 15. Comparison of DC link voltage regulation

\section{CONCLUSION}

This paper presents a modified control scheme to compensate a distribution feeder loading with non linear loads. The compensation consists of three main objectives that are i) regulation of real powers delivering to loads, ii) regulation of DC link voltage to ensure PWM converter operation, and iii) correction of power factor by using SRF method and hysteresis current controller. Modification of the control scheme made in this paper is to add the reactive power regulation into the control loop. With zero reactive power reference, unity power factor can be achieved. As a result, the modified control scheme can regulate DC link voltage and real power delivery at specified level while reactive power drawn from the load was cancelled by that injected from D-STATCOM.

\section{References}

[1] H. Akagi, Instantaneous Power Theory and Applications to Power Conditioning, New Jersey, USA.: Wiley, 2007.

[2] J. A. Momoh, Electric Power Distribution, Automation, Protection and Control, New York, USA: CRC Press, 2008.

[3] N. G. Hingorani and L. GyuGyi, Understanding FACTS Concept and Technology of Flexible AC ransmission System, New York, USA.:IEEE Press, 2000.

[4] N. G. Hingorani, "Introducing custom power", IEEE Spectrum, June 1995, pp. 41 - 48.

[5] A. Ghosh and G. Ledwich, Power quality enhancement using custom power devices, Massachusetts, USA.: Kluwer Academic Publishers, 2002.

[6] A.L. Olimpo and E. Acha, "Modeling and analysis of custom power systems by PSCAD/EMTDC," IEEE Trans. Power Delivery, vol. 17, no. 1, pp. 266-272, Jan. 2002.

[7] P. Pohjanheimo and E. Lakervi, "Steady state modeling of custom power components in power distribution networks," in Proc. IEEE Power Engineering Society winter Meeting, vol. 4, Jan. 2000, pp. 2949- 2954.

[8] A. Adya, "Application of D-STATCOM for isolated systems", IEEE Region 10 Conference (TENCOM), Vol. 3, Nov. 2004, pp. $351-354$.

[9] K. Somsai and T. Kulworawanichpong, "Modeling, simulation and control of D-STATCOM using ATP/EMTP," In Harmonics and Quality of Power, 2008. ICHQP 2008. 13th International Conference on. pp. 1-4, 2008.

[10] C. Sumpavakup, and T. Kulworawanichpong, "Distribution Voltage Regulation Under Three-Phase Fault By Using D-STATCOM", The International Conference on Electric Power and Energy Systems (EPES 2008), pp.855-859, July 2008.

[11] E. Acha, Electronic Control in Electrical Power Systems, London, UK.: Butter-Worth-Heinemann, 2001.

[12] Instantaneous Power Control of D-STATCOM with Consideration of the power factor correction. 